\title{
LITERATURA TRADICIONAL EN COLOMBIA: ENTRE EL FOLCLOR Y EL OLVIDO*
}

\author{
Traditional Literature in Colombia: \\ Between Folklore and Oblivion
}

Adrián Farid Freja de la $\mathrm{Hoz}^{1}$

\footnotetext{
* Cómo citar este artículo: Freja de la Hoz, A. F. (2021). Literatura tradicional en Colombia: entre el folclor y el olvido. Estudios de Literatura Colombiana 49, pp. 155-174. DOI: https://doi.org/10.17533/udea.elc.n49a09

1 https://orcid.org/0000-0002-0286-3147 adrian.freja@uptc.edu.co

Universidad Pedagógica y Tecnológica de Colombia, Colombia
}

Editores: Andrés Vergara Aguirre, Christian Benavides Martínez

Recibido: 13.02 .2021

Aprobado: 21.05.2021

Publicado: 30.06 .2021

Copyright: (02021 Estudios de Literatura Colombiana. Este es un artículo de acceso abierto distribuido bajo los términos de la Licencia Creative Commons AtribuciónNo comercial - Compartir igual 4.0 Internacional
Resumen: El presente artículo analiza y reflexiona sobre el papel de la literatura tradicional en Colombia en el ámbito de los estudios literarios y en las regiones del país. Luego de presentar la carencia de estudios que valoren las expresiones tradicionales, se enuncian hipótesis para explicar el desinterés por parte de la crítica literaria nacional. Enseguida se muestra el creciente interés en términos de producción bibliográfica en las regiones del país y se analiza el papel de estas obras de la literatura tradicional en términos patrimoniales y en relación con la identidad cultural territorial.

Palabras clave: Literatura tradicional en Colombia; crítica literaria en Colombia; producción bibliográfica de la literatura tradicional; literatura y región.

Abstract: This article analyzes and considers the role of traditional literature in Colombia, in the field of literary studies and in the regions of the country. After presenting the dearth of studies that value traditional expressions, hypotheses are enunciated to explain the lack of interest on the part of national literary criticism. Following, we show the growing interest in terms of bibliographic production in the country's regions and we analize the role of these works of traditional literature in heritage terms and in relation to territorial cultural identity.

Keywords: Traditional literature in Colombia; literary criticism in Colombia; bibliographic production of traditional literature; literature and region. 
En la década de los setenta, Frank Dougherty (1977) escribía que "por lo mucho que se ha comentado el aspecto conservador de la cultura popular colombiana, sorprende la escasa atención, hasta hace relativamente poco, dirigida hacia su romancero” (p. 243), y añadía en ese momento que "si no fuera por el amplio estudio realizado por Gisela Beutler en 1969, ${ }^{1}$ quizá nunca se habría dado a conocer en su plenitud esta tradición tan arraigada entre el pueblo colombiano" (p. 243). Más de cuatro décadas después, desde los estudios literarios el panorama ha variado poco. En áreas como la antropología, lingüística, musicología, entre otras, se vienen abordando obras literarias tradicionales bajo el rótulo de "folclor" desde el siglo xIx; sin embargo, entendidas como literatura (producción artística de la palabra), los avances se han dado de forma mesurada en el ámbito de la cultura de pueblos indígenas y afrodescendientes. ${ }^{2}$ Hace menos de dos décadas que empezamos a ver trabajos de grado de pregrado y de posgrado en los que se reconoce el valor literario de obras propias de la oralidad como romances, cuentos tradicionales, leyendas, relatos míticos y demás formas narrativas tradicionales, así como de expresiones líricas como las coplas y décimas, o de la diversidad paremiológica de las regiones colombianas.

La poca atención hacia un arte tradicional de la palabra oral por parte de los estudios literarios colombianos ha tenido implicaciones en la manera en que se enseña lo que es y no es literatura en colegios y universidades, así como en la manera en que se ha escrito la historia literaria de Colombia, pero sobre todo en la valoración artística de estas expresiones literarias que viven principalmente en la ruralidad. La historiografía literaria del país nos ha mostrado un panorama en donde lo tradicional del romancero, el coplerío, la paremiología popular, las leyendas, los cuentos orales, entre muchas otras expresiones de la literatura tradicional son presentadas como parte de un pasado colonial o de la época previa a la Conquista.

Esta situación tiene que ver con la manera predilecta en que se da la transmisión de la literatura tradicional: la oralidad. Como bien lo señala Paul Zumthor (1991), "a

Se refiere a la primera edición de sus Estudios sobre el romancero español en Colombia que se publica en alemán bajo el título Studien zum spanischen Romancero in Kolumbien in seiner schrijtlichen und mündlichen Überlieferung von der Zeit der Eroberung bis zur Gegenwart.

2 En lo indígena se destacan los trabajos de investigadores como Hugo Niño, Fernando Urbina, Miguel Rocha, entre otros. En lo afro se destacan apreciaciones literarias de escritores como Rogerio Velásquez, Manuel Zapata Olivella, Alfredo Vanín, entre otros, y valoraciones de nuevos investigadores que desde los distintos programas de pregrado y posgrado en literatura en el país le han apostado a darle el estatus que merece la literatura tradicional de las distintas culturas colombianas. 
nadie se le ocurriría negar la importancia del papel que representaron las tradiciones orales en la historia de la humanidad" (p. 10); sin embargo, durante el siglo xIx y buena parte del xx, a los estudios literarios en Colombia les resultó difícil pensar la literatura tradicional de transmisión oral "en términos no históricos” y, sobre todo, pensar que este tipo de literatura tradicional que no se escribe y que no tiene un único autor está viva y muy presente en nuestra cultura. No cabe la menor duda de que "nuestra cultura está impregnada de dichas tradiciones y le sería muy difícil subsistir sin ellas" (p. 10). Estas tradiciones que impregnan la cultura hicieron eco en la crítica literaria latinoamericana de finales del siglo xx. Críticos como Antonio Cornejo Polar, Martin Lienhard, Carlos Pacheco, Ángel Rama, entre otros, abogaron por la heterogeneidad, la alternatividad o la variedad de las voces de la literatura latinoamericana. Desde aquel momento, las voces tradicionales del continente empezaron a tener mayor visibilidad en ámbitos como el colombiano, en donde históricamente se había tendido a la negación del valor artístico de lo tradicional de transmisión oral, pues los ideales europeos de la Ilustración fueron asumidos en Colombia dentro de los círculos intelectuales y desde el siglo XIX nuestra cultura "culta" "lay stress on the idea of literacy and written tradition", y todo lo que se transmita oralmente ha sido estigmatizado como "crude and artistically undeveloped" (Finnegan, 2012, p. 3).

Una de las muestras de negación y marginación de las literaturas tradicionales de transmisión oral la vemos en un texto de Rafael Gutiérrez Girardot que apareció por vez primera en un artículo de 1993, publicado en la revista Marche Romane de la Universidad de Liége. Al iniciar el texto, el afamado crítico colombiano señala que:

La literatura de los pueblos ágrafos o analfabetos, llamada literatura oral, deja de serlo en su sentido prístino cuando se la transcribe y se presentan sus características como contrarias o diversas a la literatura escrita culta. No sólo porque la transcripción está sujeta a las formas consagradas por la literatura culta escrita, sino porque la llamada literatura oral se define por su referencia a la literatura culta escrita (Gutiérrez Girardot, 2006, p. I2I).

Estas afirmaciones resultan sumamente contradictorias si pensamos en que grandes obras de la literatura occidental, las homéricas y las hesíodicas por poner un clásico ejemplo, al comienzo fueron compuestas oralmente, sin referencia a la "literatura culta escrita” (esto, sencillamente, porque en aquellos tiempos no existía una literatura escrita de "referencia”). Es decir, Gutiérrez Girardot nos da a entender que los cantos de los rapsodas y aedos en la antigua Grecia, o el canto de los juglares medievales no 
tenían nada de literario. Según su visión, la Ilíada no tuvo nada de literaria mientras era cantada por rapsodas, el Beowulf o el Cantar de Mio Cid, tampoco, hasta tanto no fueron inmortalizadas en la tinta de sus primeros manuscritos.

Sin embargo, no cabe duda de que tiene mucho más sentido darle la vuelta a lo manifestado por Gutiérrez Girardot, es decir, afirmar que la literatura de los pueblos letrados e ilustrados, llamada literatura "culta", deja de serlo en su sentido prístino cuando es transmitida oralmente por el pueblo de generación en generación, y se presentan sus características como contrarias o diversas a la literatura de tradición oral. No solo porque la oralidad está sujeta a las formas consagradas por la literatura de tradición oral, sino porque la llamada literatura "culta" se define por su referencia a la literatura de tradición oral.

Son muchos los ejemplos de obras "cultas" o "letradas" que se han tradicionalizado (piénsese por ejemplo en las innumerables versiones derivadas de la historia de Cupido y Psique que aparece en La metamorfosis de Apuleyo), que se conservan en la oralidad, que se refunden en los cantos de personas ágrafas, que se refuncionalizan una y otra vez para conservar aquello que es valioso. También es cierto que la literatura "culta" se define por su referencia a la literatura tradicional de transmisión oral no solo porque primero fue la palabra hablada y cantada antes que la palabra escrita, sino porque además los temas, motivos, tópicos, imágenes que utiliza la literatura escrita "culta" en muchos aspectos son los mismos que los de la literatura tradicional de transmisión oral. Esto es, la literatura escrita se define en buena parte por su referencia a la literatura tradicional de transmisión oral. Entonces, lo dicho por Rafael Gutiérrez Girardot, paradójicamente, es cierto, pero en el sentido contrario.

La literatura tradicional de transmisión oral es un texto absolutamente vivo, abierto al cambio, que se refunde y refuncionaliza al pasar de una cultura a otra, al pasar de una generación a otra, al pasar de una geografía a otra. Esta apertura vivaz del texto tradicional va en contravía de las formas modernas de conservación y reproducción de la literatura impresa y con un único autor, enmarcadas en un mercado que se nutre de la figura del "genio creador", a pesar de que la forma oral del hecho literario "fue fundamental, y en muchos casos la única, durante gran parte de la historia literaria de la Humanidad" (González, 1990, p. 14). A pesar de esto, es un hecho que a las personas "cultas" de nuestros días y, en general, a las personas con algún grado de formación escolar, "sumergidas en la producción literaria industrial pos-gutenbergense, les cuesta 
trabajo entender el proceso de una literatura en la cual no hay una clara diferenciación entre el emisor y el receptor, y en la que la originalidad y la exclusividad son términos casi sin sentido" (González, 2003,p. 13). El paradigma de la literatura como un arte de la escritura toma mucha fuerza con el desarrollo de la imprenta y la constitución de un mercado editorial, en donde el autor o autora es el centro (Escarpit, 1971). Antes de la invención de la imprenta, la aparición de la escritura implicó un cambio profundo en el pensamiento y el desarrollo de las culturas que adoptaron esta tecnología; sin embargo, el rol social de la oralidad continuó siendo de suma importancia, al menos en el mundo occidental, hasta el auge de las urbes como centros económicos, políticos y administrativos, y el nacimiento de la burguesía. Con la imprenta, el mercado editorial relega el papel de la oralidad a un segundo plano y los juglares medievales, los "ministrantes profesionales del solaz y la alegría lo mismo en los palacios que en las plazas", los “difundidores de invenciones, gustos e ideas" (Menéndez Pidal, 1957, p.v) van desapareciendo. Como bien lo señala Ramón Menéndez Pidal, los juglares eran “editores y periodistas ambulantes", encargados de difundir "toda obra poética” a través del canto; con estos cantos no solo divulgaban las obras poéticas "mucho más eficazmente que los copistas de manuscritos", pues sus cantos también eran "noticieros sobre sucesos actuales" y "refendarios (referidores)" de "historias antiguas acreditadas" (p.v). Todo esto cambió con la imprenta, debido a que el juglar no pudo competir contra las máquinas que reproducían cientos de textos en muy poco tiempo. No obstante, es preciso advertir también que, gracias a la imprenta, el romancero y gran cantidad de obras tradicionales fueron divulgadas en los sectores más populares de la sociedad.

\section{Hipótesis sobre el desinterés}

Las razones para el poco interés de estudiosos de la literatura en la literatura tradicional en Colombia son varias y complejas; no quisiera simplificar, pero después de estudiar por años esta situación, me atrevo a señalar dos hechos que considero han influido en la tradición crítica del país.

El primero tiene que ver con el paradigma de la escritura y lo letrado presentado arriba: la revolución de una tecnología como la escritura estableció un paradigma en las culturas que adoptaron el sistema escritural como base para el pensamiento y la organización social. De ahí que, gracias al mercado editorial en el que se enmarcó la literatura desde el desarrollo de la imprenta, la literatura se pensara, antes y después 
de la constitución de la nación, principalmente desde la letra de molde. Entonces, lo que se escapaba de lo escrito no entraba en el campo de lo literario, pero, además, la estética de lo escrito tomaba cada vez mayor distancia con la estética oral, y por tanto, al comparar una expresión literaria escrita con una expresión literaria tradicional de transmisión oral, la segunda entraba en desventaja, pues la comparación no es equivalente en tanto la primera utiliza una tecnología que la otra por lo general desconoce. Esto sucedió con la crítica literaria en Colombia que utilizó siempre la vara de lo escrito para medir el valor de lo tradicional de transmisión oral. ${ }^{3}$

El segundo hecho tiene que ver con una situación extraliteraria y propia de las coyunturas sociales del país: la crítica literaria en Colombia estuvo por mucho tiempo (básicamente durante todo el siglo xIx y en diversos momentos del xx) "indisolublemente ligada a la religión y a la política. Los periódicos y revistas se fundaban con una mezcla de intenciones literarias y partidistas. La publicación aparecía como un medio de difusión 'doctrinaria"; dicho afán doctrinario comprometía el "componente literario y crítico", en tanto que este "se ponía al servicio de la causa política, como si se tratase de una servidumbre natural" (Jiménez Panesso, 1992, p. 11). De acuerdo con esto, resultaba muy difícil en Colombia "concebir la existencia de una revista literaria sin partido. La aparición de cualquier tipo de publicación periódica, por más explícitos que fueran sus objetivos culturales, suscitaba la aparición de otra como respuesta banderiza" (p. 11).

El dominio de la política sobre la crítica literaria obligaba a que las valoraciones del hecho artístico estuviesen determinadas por "ciertas peculiaridades estilísticas, derivadas unas veces de las exigencias del panfleto, la propaganda y la polémica”, pero en otros casos se exigía "la elocuencia retórica orientada a la agitación partidista" (p. 11). Además de esto, la crítica estuvo sumamente vinculada con una postura religiosa o con el alejamiento de ella, lo que se vinculaba también en Colombia con los partidos políticos, pues "dividir a los críticos literarios en conservadores y liberales era lo mismo que dividirlos en católicos y librepensadores”. Es así como, por más de un siglo, buena parte de la crítica literaria (exceptuando muy pocos casos) se presentó como una labor de militancia política y religiosa que "casi nada tuvo que ver con valoraciones puramente artísticas. Y esto puede asegurarse para toda la época anterior al Modernismo" (p. 12).

\footnotetext{
Se pueden ver algunos ejemplos historiográficos en "Territorialidad cultural y homogeneidad letrada en la región-nación. El caso de la literatura oral" de Freja de la Hoz, compilado en Escrituras del territorio/Territorios de la escritura (2020), así como en las apreciaciones que aparecen en distintas obras críticas del siglo xx. Para profundizar en las posturas de la crítica literaria colombiana sobre este aspecto es clave la revisión del libro Historia de la crítica literaria en Colombia (Jiménez Panesso, 1992).
} 
Respecto a esto es preciso mencionar que, a pesar de que en algunos casos las obras de la literatura tradicional presentan doctrinas políticas o religiosas, lo que se tradicionaliza son acciones, temas, tópicos, imágenes, etc., universales, que se desprenden de elementos doctrinales cada que se heredan en el tiempo o el espacio. Una obra tradicional doctrinal podría ser popular en el momento coyuntural, pero estaría condenada a desaparecer, es decir, no seguiría el camino de la tradición en tanto es una obra que al avocarse a una situación política o doctrinal específica pierde el interés de otros pueblos $\mathrm{u}$ otras generaciones; esto es, cuando una obra tradicional cae en el tradicionalismo dogmático, pierde su carácter tradicional y corre el riesgo de desaparecer.

Un ejemplo claro en Colombia es la pléyade de coplas sobre liberales y conservadores que, luego del asesinato de Jorge Eliécer Gaitán y durante el periodo de La Violencia y el Frente Nacional, fueron repetidas profusamente en uno y otro bando para hacer burla del opositor, pues se trataban de los dos únicos partidos políticos en Colombia. Sin embargo, a pesar de estar tan documentadas y permanecer en la memoria de muchas personas de edad avanzada, estas coplas tienen poco sentido hoy en Colombia, un país que cuenta actualmente con 15 partidos políticos - entre los que todavía cuentan el Liberal y el Conservador, pese a su absoluta decadencia ideológica- $-{ }^{4}$ Aunque estas obras se puedan seguir cantando en ciertos lugares, lo que se mantiene es el interés en el uso de los tópicos, las imágenes, las analogías, las metáforas, la sonoridad, pero no en el hecho coyuntural. Esto es evidente en romances que en su momento fueron históricos, pero que hoy son rondas infantiles, como el conocido Mambrú. En el canto infantil poco o nada queda del duque de Marlborough, en realidad nada interesa sobre la vida del duque. Mambrú dejó de ser un duque para convertirse en un personaje atemporal, ahistórico, asexuado, un personaje maleable que se adapta a la imaginación de cada niño o niña que canta tan sonora canción.

La variabilidad de la literatura tradicional es la que permite afirmar que Frank Dougherty se equivocaba al relacionar el conservadurismo que tanto ha dominado la cultura colombiana con la valoración del romancero tradicional colombiano. Lo tradicional no es lo que se queda anclado en el tiempo y el espacio, es todo lo contrario;la tradición está variando constantemente para ajustarse al contexto de la comunidad que la acoge, mientras que el tradicionalismo sí pretende anclarse espaciotemporal4 Tal es la decadencia que es común encontrar candidatos avalados y apoyados simultáneamente por el partido
Liberal y el Conservador. 
mente con fines ideológicos. No se puede confundir una cultura conservadora (tradicionalista), regida bajo unos principios ideológicos establecidos, con la tradición que está variando segundo a segundo y adaptándose a los contextos más disímiles.

Un ejemplo de tradicionalismo dogmático es el paradigma del "gramaticalismo" que en Colombia tuvo una muy fuerte presencia en la crítica literaria. David Jiménez Panesso (1992) afirma que el “imperio del 'gramaticalismo' en Colombia sustituyó, con mucha frecuencia, al análisis literario, pasando por valoración estética y, en ocasiones, casi religiosa” (p. 12). Religiosa en el sentido de que la gramática de la lengua castellana, y su correcto uso en naciones independientes como Colombia (con una fuerte relación cultural de hispanidad y una desbocada nostalgia por la "Madre Patria”), se equiparó con seguir los mandatos divinos (leyes religiosas) y cumplir los mandatos terrenales (leyes nacionales). Una muestra de esto la encontramos en el discurso pronunciado por Marco Fidel Suárez (1856-1927) a propósito del idioma castellano en Antioquia, titulado "El castellano en mi tierra". En este discurso, Fidel Suárez (1952) afirmó que "El que altera perversamente la sintaxis... no sólo es prevaricador del hablar... sino de su raza y de su patria", entendidas estas como el "Reinado de Dios" (p. 321); es decir, el prevaricador del hablar atenta no solo contra la "belleza" y la "pureza" del idioma castellano, sino también contra su "raza", su "patria" y por ende contra "Dios".

Aquí queda claro que una cosa es la ideología conservadora que toma la gramática como un eje articulador de sus creencias, y otra muy distinta la manera en que los usos gramaticales van variando de acuerdo con el territorio al que llegue una obra tradicional o al momento histórico. Ideológicamente, la gramática es una preceptiva fija de la lengua que debe cumplirse a cabalidad, mientras que para la lengua que les da vida a las obras literarias de transmisión oral, la gramática es maleable y se adapta a los usos y costumbres de pueblos, pero de acuerdo con sus propios usos lingüísticos, con sus paisajes, etc. La literatura tradicional es antigramatical, en el sentido que no se aferra preceptivamente a una gramática, sino que transita por todos los usos y variaciones gramaticales de una lengua en los distintos territorios a los que llega. Esta particularidad se explica en tanto, como ya se dijo, se trata de un fenómeno colectivo, comunitario, que se apropia de las formas tradicionales para adaptarlas a entornos culturales particulares con diferencias regionales expresadas en el uso del idioma, en el discurso, en las variaciones narrativas, en las particularidades rítmicas de las obras 
y en todo aquel rasgo cultural que le dé vida y valor colectivo a producciones que encarnan historias o imágenes de siglos atrás. Allí se encuentra entonces la importancia de llevar a cabo un estudio regional de la literatura tradicional. Cada región reelabora y refuncionaliza una serie de elementos de la obra tradicional para que tenga posibilidades de existencia dentro del territorio regional.

Todo esto ha influido para que la literatura tradicional haya sido olvidada y marginada por la crítica literaria en Colombia. No sorprende entonces que los pocos estudios de la literatura tradicional, entendida como literatura y dentro de un gran marco tradicional de herencia hispánica y universal, hayan sido llevados a cabo por investigadores extranjeros. Asimismo, lo dicho arriba explica de cierta manera las razones por las que los críticos literarios en Colombia veían con absoluto desdén las producciones de la literatura tradicional, principalmente la de transmisión oral.

\section{Las recopilaciones de la literatura tradicional en Colombia}

Contrariamente, la atención que le ha prestado la antropología y la musicología al fenómeno de la literatura tradicional en Colombia no ha sido poca. Desde la segunda mitad del siglo xıx podemos encontrar algunos intentos por llamar la atención sobre la presencia y la particularidad nacional. Sin embargo, es en la primera mitad del siglo xx cuando antropólogos, musicólogos y algunos autodenominados "folcloristas" o "folclorólogos" se dan a la tarea de recopilar a lo largo y ancho del territorio las expresiones literarias tradicionales.

No obstante, es sabido que durante el siglo xıx, bajo la influencia del ambiente romántico traído de Europa, dos grandes escritores en Colombia valoraron enormemente la literatura tradicional de transmisión oral presente en el pueblo llano. Jorge Isaacs (1837-1895) y Rafael Pombo (1833-1912) dejaron registros de sus intereses en este tipo de literatura. Un genuino interés por el valor artístico de los versos literarios manifestado en las recopilaciones hechas en trabajos de campo por distintos territorios rurales del país, así como en ambientes urbanos en donde la literatura tradicional se conserva en la oralidad de todas las clases sociales.

Una parte de las recopilaciones de obras de la literatura tradicional de transmisión oral realizadas por Jorge Isaacs apareció publicada póstumamente bajo el título Canciones y coplas populares. En el Prólogo, el maestro Guillermo Abadía Morales (1985) señalaba: 
En los archivos de la Biblioteca Nacional de Colombia se han hallado dos fascículos manuscritos de singular importancia. Se trata de una colección en dos partes tituladas "Canciones populares" y "Coplas populares". Lo singular está en que el compilador de ella es el eminente hombre de letras autor del bellísimo relato lírico María, obra clásica de la literatura colombiana, don Jorge Isaacs. [...] Por otra parte, es poco conocido y estudiado como etnólogo o historiador y su obra Las tribus indigenas del Magdalena no ha inquietado mucho a la crítica. Sin embargo, ya su maestría literaria es buen respaldo para acreditar la calidad del coplerío recogido en estos fascículos. Yo, como amanuense que también fuera y antologista de la poesía popular, juzgo que en esta selección no hay copla alguna que pueda tacharse de mediocre o desechable como muchas que han recibido edición en volumen a pesar de su dudosa calidad. El acervo presente consta de 494 ejemplos, es decir, casi medio millar" (p. 3).

No sorprende el hecho de que las obras de la literatura tradicional de transmisión oral recopiladas por Isaacs no fuesen publicadas en vida, pues en el siglo xIx este tipo de obras literarias no merecieron ningún tipo de interés por parte de la crítica, en tanto no fueron consideradas como obras artísticas. Por su parte Rafael Pombo, "aristócrata del arte, cantor de altísimos ideales", fue realmente un conocedor del "gran precio de la poesía popular y la sentía con toda su ingenuidad y frescura" (Gómez Restrepo, 1953, p. 41). Muestra de ello son las distintas recopilaciones que realizó durante su vida y que jamás fueron publicadas. ${ }^{5}$ Como lo señala Gisela Beutler (1977), luego de conocer de primera mano una serie de cuadernillos manuscritos del gran poeta colombiano, "Pombo recopiló [...] una colección de canciones populares de tradición oral, sobre todo de coplas, pero también de otras formas líricas, que le parecieron dignas de atención, con la documentación precisa de su origen” (p. 156). En uno de los cuadernos revisados por Beutler aparecen las siguientes secciones:

El cuaderno empieza con "Versos populares de Colombia". Los primeros dos capítulos son "Versos que me dictaron bogas del alto Magdalena en 1854 "; una tercera parte son "Versos que cantan en Guasca (Cundinamarca)". Además: "Versos que me decía mi padre", o "Dichos por mi mamá", "oída a un borracho", "oídos a otros", o con indicación de los nombres de los recitadores (p. is б).

Es preciso resaltar el muy honesto y profundo interés de este "aristócrata del arte" en la literatura tradicional que circulaba en boca del pueblo llano, de los bogas del río Magdalena, de los cantantes populares, de los borrachos, o incluso de sus padres. Esto muestra que la literatura tradicional no solo está en boca del pueblo menos letrado, sino que también aparece en las clases más altas de la sociedad, como la clase en la que nació y a la que perteneció Pombo durante toda su vida. El interés fue realmente

Si estas recopilaciones se publicaran, sería realmente un gran aporte para literatura tradicional del país. Este es un llamado a que los herederos de Pombo que conservan estas obras las cedan para su publicación. 
grande y, según lo afirma Beutler, "el poeta contaba los versos que había copiado en el cuaderno, y registró para el año de 1876 — durante el cual hizo la mayoría de las anotaciones - el número de 3070, sin contar las coplas de doble significado” (p. 156).

De acuerdo con esto, es claro que el interés por la literatura tradicional de transmisión oral no era poco en el siglo xIx; de hecho, el mismo Vergara y Vergara (1867) muestra en el capítulo final de su historia varias expresiones de poesía popular que él mismo ha escuchado; sin embargo, se atreve a decir por ejemplo que los cantos llaneros “tomaron la forma de metro y la idea de los romances españoles; pero desecharon luego todos los originales, y compusieron romances suyos para celebrar sus propias proezas” (p. 518). En 1906, Ramón Menéndez Pidal (1928) iniciaba su texto "Los romances tradicionales en América", citando a Vergara y Vergara y señalando que, a principios del siglo xx, en España, él o nadie conocía "ningún romance tradicional en América” y, por tanto, en ese momento, se podía "negar la existencia del género" (p. 184) si se tenían en cuenta declaraciones como las de Vergara y Vergara. Por supuesto, en 1905, al llegar a América, se da cuenta no solo de la existencia de romances tradicionales en nuestro continente, sino de la variedad y la popularidad de estos en distintas regiones de los países de su recorrido.

Vergara y Vergara estaba equivocado sobre la presencia de literatura tradicional de transmisión oral en la Nueva Granada, básicamente por un desconocimiento de los territorios alejados de las urbes, de la cultura popular, oral y tradicional del pueblo llano, pero también por haber estado enfocado en la "alta cultura" de la Nueva Grana$\mathrm{da}$, en la cultura de los criollos. Cuando se refiere a la literatura popular, le reconoce que, "considerada en abstracto, no deja de tener fases interesantes y demostrar alguna riqueza intelectual en el bajo pueblo de la Nueva Granada”, pero le parece que todavía no existe una verdadera literatura popular, puesto que "no teniendo tradiciones comunes, la poesía no podía hacerse popular; ni la raza indígena, ni la blanca podían tener simpatías por los cantos de los negros; ni estos por las tradiciones españolas de sus amos o por los vagos recuerdos de los indios" (Vergara y Vergara, 1867, p. 509). Para explicar la supuesta carencia de poesía oral en el país, Vergara y Vergara presenta una hipótesis: para que exista una literatura nacional popular debe existir una unidad cultural determinada por la lengua, las costumbres y la religión.

De acuerdo con lo señalado arriba, es posible afirmar que, a pesar de que historiadores como Vergara y Vergara, y Otero, escritores como Isaacs y Pombo, filólogos 
como Rufino José Cuervo, entre otros intelectuales del siglo xix y principios del xx, se interesaron por las obras de la literatura tradicional en boca del pueblo llano, la crítica literaria en Colombia le dio la espalda a este tipo de producciones artísticas no solo durante el siglo xix y principios del xx, sino que en pleno siglo xxi llama la atención la poca atención a estas producciones.

Por tal motivo, es preciso destacar y agradecer el interés y la labor de la antropología, la musicología, la etnomusicología, la etnolingüística, la historia, e incluso la sociología, la psicología y los estudios culturales. En Colombia es posible hablar de un gran acervo de la literatura tradicional en las distintas regiones del país, gracias principalmente a la antropología y la musicología, disciplinas que desde hace más de un siglo se han dado a la tarea de recopilar diferentes tipos de expresiones tradicionales de la palabra en comunidades pertenecientes a muy variadas regiones del territorio nacional. Evidentemente, el nombre dado a las expresiones literarias tradicionales ha sido el de "folclor" y la valoración ha sido antropológica, lingüística o musical, pero no literaria.

Veamos entonces un panorama de las recopilaciones de la literatura tradicional en Colombia y del potencial para el estudio de estas expresiones dentro de los estudios literarios del país. Para tal fin se llevó a cabo una búsqueda bibliográfica con casi cinco mil registros de los cuales se seleccionaron inicialmente más de mil, ${ }^{6}$ pero se hizo luego una depuración teniendo en cuenta que el fin de la publicación fuese directamente la literatura tradicional en Colombia y que fuese en español. Encontré entonces 507 publicaciones con estas características (principalmente publicaciones que recopilan coplas, leyendas, cuentos, refranes, romances, adivinanzas y décimas). De estas, 108 son artículos publicados en revistas, las restantes son libros, publicados la mayoría por instituciones de carácter público nacional, regional, departamental o municipal. Los textos encontrados van desde 1881 hasta 2019. En la figura 1 podemos ver la tendencia de crecimiento de las publicaciones a partir de mediados de la década de 1930:

Inicié con búsquedas en bases de datos online como Worldcat, Google Books, Internet Archive, entre otros; en segunda instancia busqué en las dos principales bibliotecas de Colombia: la Biblioteca Luis Ángel Arango (y su red de bibliotecas del Banco de la República) y la Biblioteca Nacional (que depende del Ministerio de Cultura), luego en las bibliotecas de las principales universidades de Colombia a las que tuve acceso (Universidad de los Andes, Universidad Nacional de Colombia, Universidad Pedagógica y Tecnológica de Colombia), así como en bibliotecas especializadas como la del Patronato Colombiano de Artes y Ciencias (una pequeña biblioteca en el centro de Bogotá especializada en "folclor"). Sin embargo, es claro que muchas publicaciones locales sin registro ISBN o que nunca fueron catalogadas dentro de ninguna biblioteca se pudieron escapar de esta recopilación bibliográfica. 
Fuente: Elaboración propia a partir de la bibliografía compilada para esta investigación y disponible en www.literaturatradicional.co

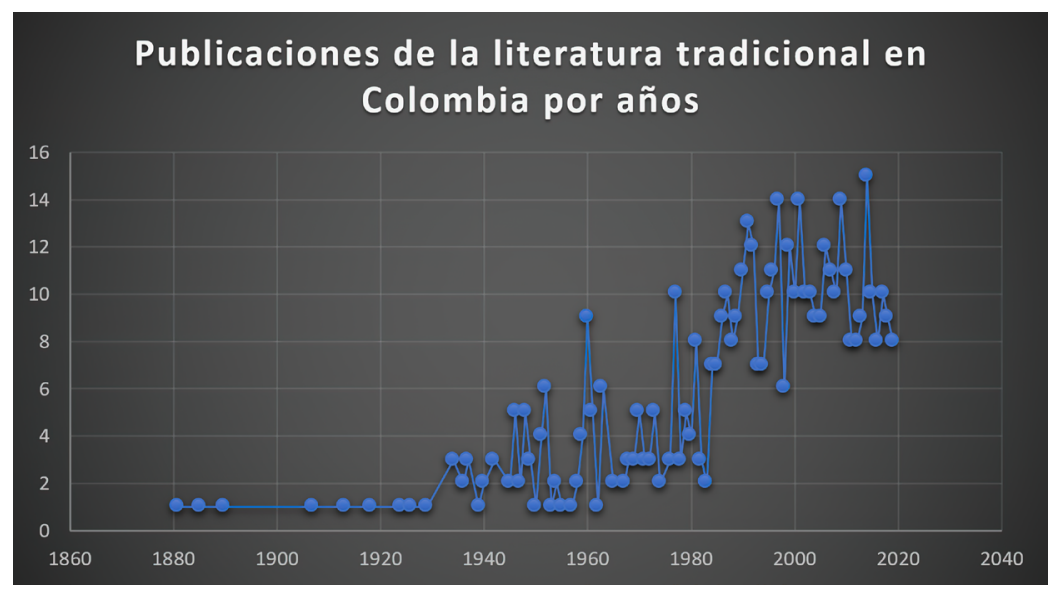

Figura 1. Publicaciones de la literatura tradicional en Colombia por años

Cuando agrupamos por décadas (véase la figura 2), observamos con mucha más claridad la existencia de un comportamiento creciente continuo:

Fuente: Elaboración propia a partir de la bibliografía compilada para esta investigación y disponible en www.literaturatradicional.co

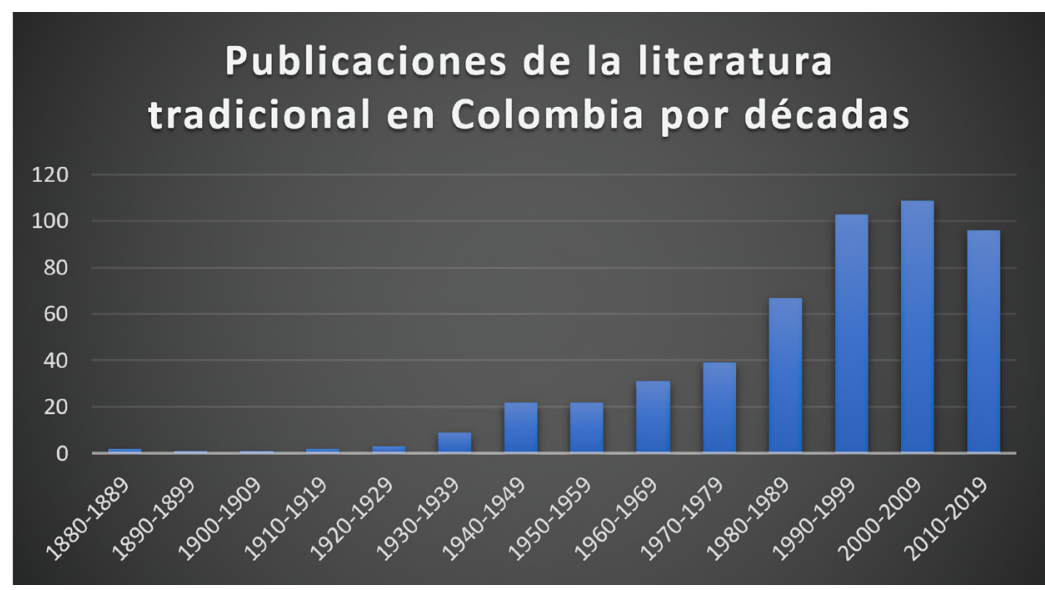

Figura 2. Publicaciones de la literatura tradicional en Colombia por décadas

En esta gráfica, la curva de publicaciones por décadas toma un impulso luego de la década de 1930. La tendencia del crecimiento en las publicaciones sobre expresiones literarias tradicionales, durante la segunda mitad del siglo xx, es muestra fehaciente del aumento en el interés por este tipo de producciones, entendidas como "folclor" y 
pensadas como un eje central dentro de las construcciones identitarias y patrimoniales de las regiones del país.

Esta tendencia en las publicaciones de literaturas tradicionales va en contravía de lo que varios autores señalan sobre el papel y el impulso que se le dio al folclor, principalmente en la segunda mitad del siglo xIx y principios del $\mathrm{xx}$, de parte de varios gobiernos de América Latina que "se apoyaron en el folclor y la cultura popular como un mecanismo para construir identidades y fortalecer los sentimientos nacionalistas, al imprimir a las tradiciones culturales campesinas un carácter positivo que invocaba la unidad nacional" (Sánchez Mejía y Santos Delgado, 2014, p. 146). La gráfica tampoco refleja que "de manera paralela al rol del Estado, un grupo de intelectuales, con sus estudios, crónicas y ensayos, cumplieron un papel importante en la construcción de identidades nacionales", sobre todo cuando se trataban de "escritos sobre el folclor" que "tuvieron una importancia relevante durante la primera mitad del siglo xx para un sector de pensadores y artistas americanos, en sus esfuerzos por crear, fortalecer y fomentar identidades regionales y nacionales" (p. 146).

Puede que los mencionados autores tengan razón y los afanes de constitución identitaria se dieran en términos políticos en la segunda mitad del siglo xIx y la primera del xx, pero nuestra evidencia de publicaciones sobre literaturas tradicionales resalta el interés en la segunda mitad del siglo xx y comienzos del xxi. Básicamente porque la construcción de identidad es un proceso constante, pero también porque los avances tecnológicos han permitido que la recolección de literatura tradicional de transmisión oral sea mucho más sencilla y los costos de publicación en papel sean cada vez menos onerosos. Asimismo, la aparición de la Revista Colombiana del Folclor en 1947 le da apertura a un espacio para la publicación de artículos que recogen diversas muestras de la literatura tradicional colombiana. De igual forma, otra poderosa razón es el fantasma de la desaparición de las prácticas de la tradición oral, que bajo el lema de "las palabras se las lleva el viento y lo escrito, escrito está" ha justificado durante años el proceso de supuesto "rescate" o "conservación" de la oralidad de obras literarias a través de la impresión en letra de molde de una gran variedad de coplas, romances, décimas, cuentos, leyendas, refranes, etc., de las distintas regiones del país.

Este interés en el "rescate" o "conservación" de lo oral a través de lo escrito se enmarca en el paradigma letrado, en la idea de que si no se escribe, no posee validez artística o literaria, desconociendo que el valor real de las expresiones tradicionales 
de transmisión oral está en la puesta en escena, en la perfomancia de la palabra, en la integración de la palabra artísticamente elaborada con las prácticas comunitarias. No obstante, agradezco enormemente los esfuerzos de recolección y publicación de las literaturas tradicionales de transmisión oral, pues nos dan una muestra importante de las transformaciones y conservaciones de unidades mínimas que representan la tradicionalidad de motivos, temas, tópicos, estructuras rítmicas, imágenes, tropos, entre otras muchas características heredadas entre amplias distancias temporales o espaciales, y que analizo en este trabajo.

De otra parte, además del interés creciente de las últimas décadas por publicar textos de literatura tradicional de transmisión oral, al observar la muestra de publicaciones llama la atención que, al agrupar por tipo de obras de la literatura tradicional, aparecen unos géneros predominantes dentro del espectro. Como se muestra a continuación, la leyenda es el género narrativo que mayor acogida tiene en la edición de los textos publicados. En la figura 3 se muestra la distribución de los principales tipos de obras de la literatura tradicional en las publicaciones recopiladas:

Fuente: Elaboración propia a partir de la bibliografía compilada para esta investigación y disponible en www.literaturatradicional.co

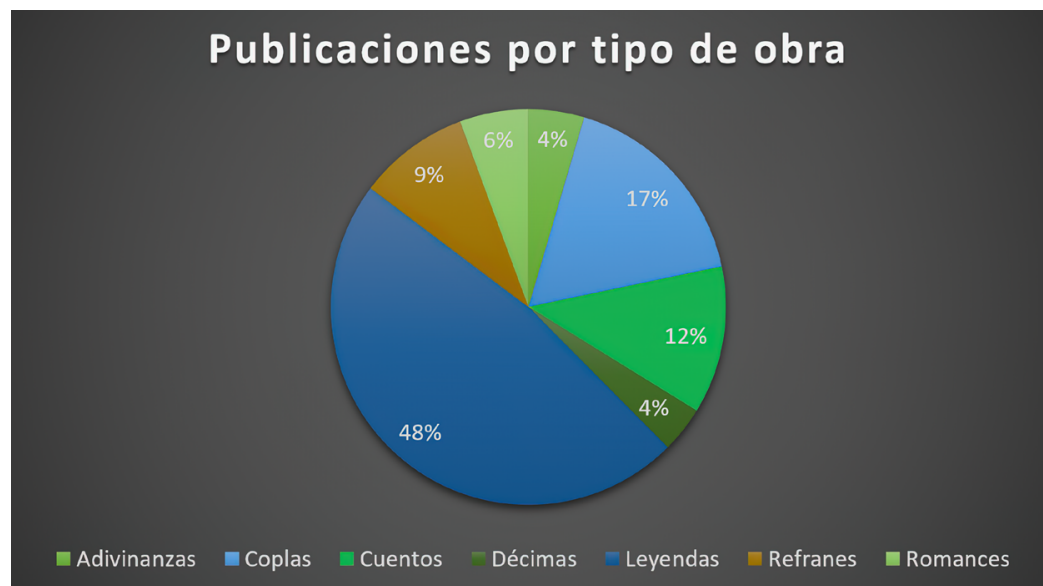

Figura 3. Publicaciones de la literatura tradicional en Colombia por tipo de obra

E1 hecho de que la leyenda ocupe casi la mitad de la torta se explica, por un lado, gracias a que dicho género es el que más relación tiene con el lugar geográfico en donde aparece. La leyenda necesita de un lugar conocido por una comunidad para cobrar sentido; por tanto, en términos de identificación y patrimonialización de un 
lugar específico, tiene una gran ventaja frente al cuento, los romances y los géneros líricos. Cada región del país se identifica con una serie de leyendas que, aunque se repitan en lugares lejanos, están asociadas a personajes o sitios muy específicos dentro de un territorio valorado por la comunidad que habita dicha espacialidad. Es decir que en las apuestas por la publicación de textos que contribuyeran a la constitución o consolidación de identidades locales, regionales o nacionales, la leyenda es el tipo de narrativa que más se ajusta a estos intereses.

Luego de la leyenda, aparece la copla como el siguiente tipo de obra de la literatura tradicional que más se publica. La copla en Colombia es la "forma estrófica de mayor popularidad y acogida", es fundamental en "la composición y difusión de un sentir colectivo", debido a que "se ha insertado de forma sincrética en las dinámicas socioculturales" de las distintas regiones de Colombia, sobre todo "en las dinámicas relacionadas con la producción agrícola y con aquellas de las tradiciones religiosas o rituales" (Freja de la Hoz, 2015, p. 81). Al estar vinculada con los cantos tradicionales de cada región, la copla es un patrimonio musical que se abraza con las prácticas y saberes comunitarios, siendo además una forma de improvisación fundamental de versos en todas las regiones del país. A pesar de que se improvisa, las coplas improvisadas conservan un halo de tradicionalidad a partir de versos que encierran imágenes, tropos, tópicos o motivos que se pueden rastrear en la literatura de tradición hispánica.

En seguida aparecen los cuentos y los refranes como las formas que mayor atención han tenido en la divulgación editorial. La particularidad compartida de los cuentos y los refranes que les permite ser tan difundidos es el valor didáctico moral que encierran estas expresiones de la palabra. La comunidad que encuentra en cuentos y refranes valores que son propios de su universo axiológico se apropia de dichas historias y de dichas paremias, adaptándolas al contexto, es decir, tradicionalizándolas según diversos elementos del sistema cultural en el que se envuelve la región.

De acuerdo con esto, las publicaciones de las literaturas tradicionales son parte importante de la identidad de comunidades en Colombia; por tanto, no se pueden desligar de una pertenencia espacial en la que los territorios son protagonistas. Al carecer de un autor, las obras tradicionales son producto de una comunidad y por tanto su vinculación se referencia al espacio de la comunidad; por ejemplo, se habla de "Las leyendas de Cartagena”, "La copla de Boyacá" "Los cuentos del Pacífico", "Los refranes del Gran Tolima”. La región se convierte entonces en el autor de las obras 
tradicionales, debido a que esta literatura no tiene dueño, pero sí fronteras invisibles. Fronteras que responden a dos claros aspectos: el político y el cultural. Las fronteras políticas son aquellas que se demarcan con los límites del corregimiento, la vereda, el municipio, el departamento o la nación, y que tienen una pertenencia administrativa que genera indudablemente desde su establecimiento una serie de identidades comunitarias, pero sobre todo una serie de manejos económicos y políticos que particularizan a la comunidad encerrada dentro de los límites invisibles nacionales, departamentales, municipales e incluso veredales. De otra parte, se encuentran las fronteras culturales, las cuales transgreden los límites administrativos y responden realmente a una pertenencia cultural que abarca comunidades que comparten sociolectos y tradiciones culturales de distinto tipo: musicales, gastronómicas, literarias, etc.

Dentro de las fronteras culturales, la pertenencia espacial encontrada en las publicaciones se presenta en relación con regiones que van más allá de un municipio (regiones extramunicipales), regiones que van más allá de un departamento (regiones extradepartamentales) y regiones que van más allá de la nación misma (regiones extranacionales). También se encuentran algunas delimitaciones que no obedecen a criterios de división política, sino que se asocian con lugares que pueden pertenecer a varios municipios o departamentos. Es decir, de igual forma nos enfrentamos a fronteras culturales cuando los fenómenos literarios se asocian con un río, un lago, una ciénega o una sierra. Veamos la figura 4:

Fuente: Elaboración propia a partir de la bibliografía compilada para esta investigación y disponible en www.literaturatradicional.co

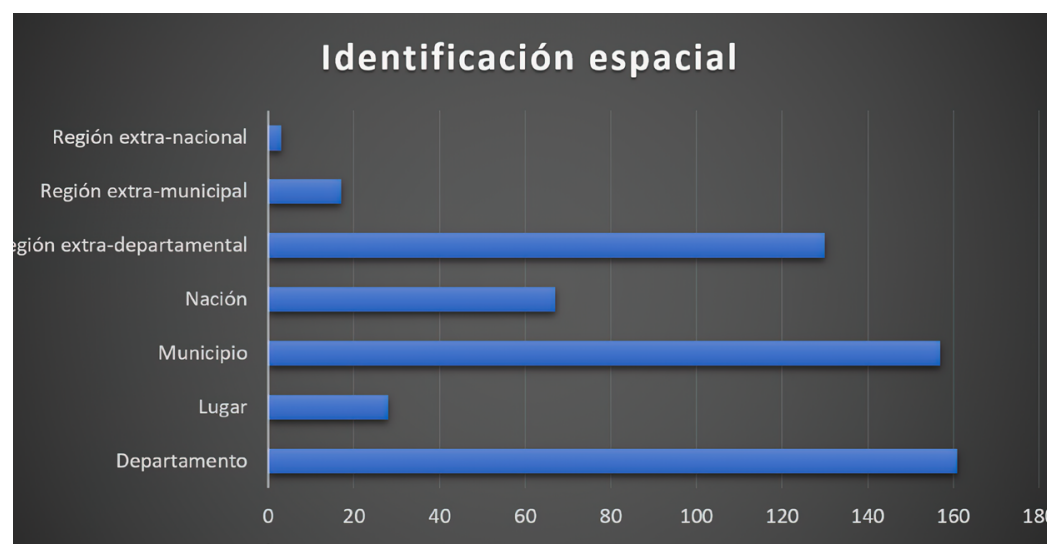

Figura 4. Identificación espacial de las literaturas tradicionales en Colombia 
En este gráfico se evidencia que el predominio de las identificaciones por territorios de las publicaciones de la literatura tradicional en Colombia lo tienen las delimitaciones político-administrativas. La mayoría de las publicaciones responden a la identificación con un departamento o un municipio. Esto se explica fácilmente teniendo en cuenta que estas divisiones crean realmente una identidad territorial, pero sobre todo se explica gracias a que buena parte de dichas publicaciones fueron financiadas por entidades territoriales municipales o departamentales como alcaldías, casas de la cultura, secretarías de cultura, entre otras, lo que implica que la identificación espacial se dé a partir de los límites territoriales de dichas entidades.

No obstante, es preciso resaltar que las regionalizaciones que van más allá de las fronteras político-administrativas no son pocas y nos permiten identificar las zonas del país que comparten elementos culturales más allá de las fronteras invisibles de la política e incluso más allá de las fronteras geográficas. Regiones como el "Gran Tolima”, que va más allá de los límites del departamento del Tolima, o los "Llanos Orientales", que se entiende como una zona que comparte una característica geográfica, o la "Región Caribe", que se identifica en varios textos con la conjunción de elementos idiosincráticos que van más allá del litoral, conforman el mapa de las regiones culturales en Colombia.

La presencia y el papel de la literatura tradicional en las regiones de Colombia evidencian su importancia en términos patrimoniales como generadora de identidad, pero sobre todo como elemento fundamental en la constitución de memorias ligadas con regiones o espacios que comparten expresiones culturales como ejes de diferenciación con otros territorios. Esto contrasta con la poca atención prestada durante décadas en los estudios literarios del país.

Los trabajos de Gisela Beutler en la década de 1960 marcaron un hito fundamental en la valoración estética de obras líricas y narrativas de la literatura tradicional en las regiones del país. No obstante la labor de Beutler, han sido pocos y aislados los trabajos que, desde aquella época, han logrado analizar y reflexionar sobre las apropiaciones que se han dado de expresiones tradicionales de variadas latitudes y culturas del planeta en los diversos territorios del país.

$\mathrm{El}$ incremento en el interés por las publicaciones de literatura tradicional (la mayoría de las veces bajo el rótulo de "folclor") en las regiones muestra cómo estas formas artísticas en prosa y en verso (coplas, décimas, romances, seguidillas, leyendas, 
cuentos, relatos míticos, entre otros) son valoradas territorialmente por la manera en que se constituyen en parte integral del patrimonio cultural de cada lugar. Llama mucho la atención que estas expresiones vienen en su mayoría de obras hispánicas, grecolatinas y africanas con gran antigüedad. Cuentos que ya aparecen en Apuleyo, en obras de la Edad Media, o en grandes producciones del Siglo de Oro español se encuentran en distintas regiones de Colombia bajo ingeniosas variantes que proyectan elementos de la cultura local para generar identidad en cada obra, con el fin de que trascienda y se herede en el territorio.

La importancia territorial y la gran tradición que encierran estas obras debería ser motivo suficiente para que en los programas de formación literaria de todos los niveles aparezcan estos fenómenos literarios - tan locales que se conectan con los temas y formas literarias más universales posibles - como parte fundamental de la riqueza literaria del país. Reconocer estas obras más allá de la idea de "folclor" es un paso esencial para evitar que el olvido se apodere de estas expresiones y para que entendamos que en la oralidad del campo y la ciudad viven obras que heredan lo mejor de la literatura del planeta bajo transformaciones regionales de gran valor artístico.

\section{Referencias bibliográficas}

Abadía Morales, G. (1985). Prólogo: Un hallazgo literario. En J. Isaacs. Canciones y coplas populares (pp. 4-7). Bogotá: Procultura.

Beutler, G. (1977). Estudios sobre el romancero español en Colombia. Bogotá: Instituto Caro y Cuervo.

Dougherty, F. (1977). Romances tradicionales de Santander. Thesaurus: Boletin Del Instituto Caro y Cuervo 32 (2), pp. 242-272.

Escarpit, R. (1971). Sociología de la literatura. Barcelona: Oikos-Tau.

Finnegan, R. (2012). Oral Literature in Africa. Cambridge: Open Book.

Freja de la Hoz, A. F. (2015). La literatura oral en Colombia. Romances, coplas y décimas en el Pacífico y el Caribe colombianos. Bogotá: Universidad Nacional de Colombia.

Gómez Restrepo, A. (1953). Historia de la literatura colombiana. Bogotá: Ministerio de Educación Nacional.

González, A. (1990). El motivo como unidad narrativa a la luz del romancero tradicional. México: E1 Colegio de México.

González, A. (2003). El romancero en América. México: Editorial Síntesis.

Gutiérrez Girardot, R. (2006). Pensamiento hispanoamericano. México: UNAM. 
Jiménez Panesso, D. (1992). Historia de la crítica literaria en Colombia. Siglos XIX y XX. Bogotá: Universidad Nacional de Colombia-Instituto Colombiano de Cultura.

Menéndez Pidal, R. (1928). Los romances tradicionales en América. En El romancero: Teorías e investigaciones (pp. 184-229). Madrid: Editorial Páez.

Menéndez Pidal, R. (1957). Poesía juglaresca y orígenes de las literaturas románicas. Madrid: Instituto de Estudios Políticos.

Sánchez Mejía, H. R. y Santos Delgado, A. (2014). Los usos del folclore y la construcción de una identidad regional “costeña” y nacional en la obra de Antonio Brugés Carmona, 1940-1950. Revista de Estudios Sociales 49, pp. 145-158. DOI: https://doi.org/10.7440/res49.2014.11

Suárez, M. F. (1952). Estudios escogidos. Bogotá: Biblioteca de Autores Colombianos.

Vergara y Vergara,J. M. (1867). Historia de la literatura en Nueva Granada. Santa Fe de Bogotá: Imprenta de Echeverría Hermanos.

Zumthor, P. (1991). Introducción a la poesía oral. Madrid: Taurus Humanidades. 